\title{
Research on the Volatility of China's Real Estate Stock Market
}

\author{
Zhou Lingyu \\ Institute of economics, Shanghai University \\ Shanghai, China \\ E-mail: 2278141503@qq.com
}

\begin{abstract}
In order to understand the volatility and risks of China's real estate stock market, it is particularly important to effectively measure the daily fluctuations in the real estate stock market. This article analyzes China's real estate industry index and five representative companies of real estate listed companies in China (Wanke000002.SZ, China Overseas Development 00688.HK, China Evergrande 03333.HK, Country Garden 02007.HK, Poly Real Estate 600048. SH). The daily return rate data of is an experimental sample. Eviews tool is used to analyze the fluctuation characteristics of their daily returns. The results show that only the Poly Real Estate and real estate industry indices in the five listed companies and the real estate industry index are auto-correlation-only real estate. The industry index has ARCH effect, and further learns from GARCH and TARCH modeling that the volatility of the daily return rate series of the real estate industry index is aggregative and persistent, and there is asymmetry and leverage effect of the impact, which shows that the investor has an impact on the market. The negative news is very sensitive. When the stock price falls, it will sell the stock and cause the stock price to fluctuate.
\end{abstract}

Keywords-Volatility; Leverage effect; GARCH model; TGARCH model

\section{THE LITERATURE REVIEW}

Over the years, domestic and foreign scholars have studied capital markets in many ways, among which there are many studies on price fluctuations in the stock market. For example, I.-Yuan Chuang, Jin-Ray Lu, and Pei-Hsuan Lee (2007) analyzed the volatility forecasting performance of GARCH models based on various distribution hypotheses in the context of stock market indices and exchange rate gains. Out-of-sample volatility forecasting results show that the GARCH model combines logical distributions [2]; Hung (2009) believes that asymmetric GARCH models can better measure the volatility of stock prices [3]; Sabiruzzaman et al. (2010) trade in Hong Kong stocks. The index is a sample. The accuracy of the stock price volatility is compared between the GARCH model and the TGARCH model. The results show that the TGARCH model can well describe the leverage effect of the stock market under asymmetric information, and its estimation result is better than the GARCH model [4]. In addition, many scholars in China have conducted a lot of research on stock prices. $\mathrm{Wu}$ Zhen and others used wave theory and clustering wavelet packet models to empirically study stock price fluctuations [5]; Wang Mingzhao et al. used the GARCH family model for Shanghai. Deep stock market returns and stock price volatility clustering have been tested [6]; Jia Fanglin proposes a behavioral model to study investors' actual investment behaviors, and on this basis, analyzes the causes of stock price volatility in China in order to explain stock price fluctuations. Provides another new idea [7].

This article mainly analyzes the volatility of China's real estate industry's stock price and understands the characteristics of China's real estate stock price volatility, so as to provide a theoretical basis for stock price forecasting and investor investment.

\section{DESCRIPTIVE ANALYSIS}

\section{A. Sample data selection and timing analysis}

This article will conduct empirical research on the returns of the stock index of the top five companies in China's listed companies' real estate industry index and China's top five real estate listed companies. Since the volatility of the stock index is mainly represented by the volatility of the series of returns, this paper uses the closing price of the stock index to calculate the yield of the stock index.

The formula is: $r_{t}=\ln \left(e_{t}\right)-\ln \left(e_{t-1}\right)$

where $r_{t}$ is the return rate of the stock index, $e_{t}$ and $e_{t-1}$ are the closing price of the stock index for the $\mathrm{t}$-th period and the $\mathrm{t}$ 1 period respectively.

This article selects the daily closing prices from January 5 , 2010 to June 30, 2017 as sample data. Due to the different amount of data, the five companies were divided into three categories based on Hong Kong stocks, Shenzhen stocks and Shanghai stocks. Eviews software was used to conduct empirical analysis of the real estate industry index and the daily returns of the five companies. 

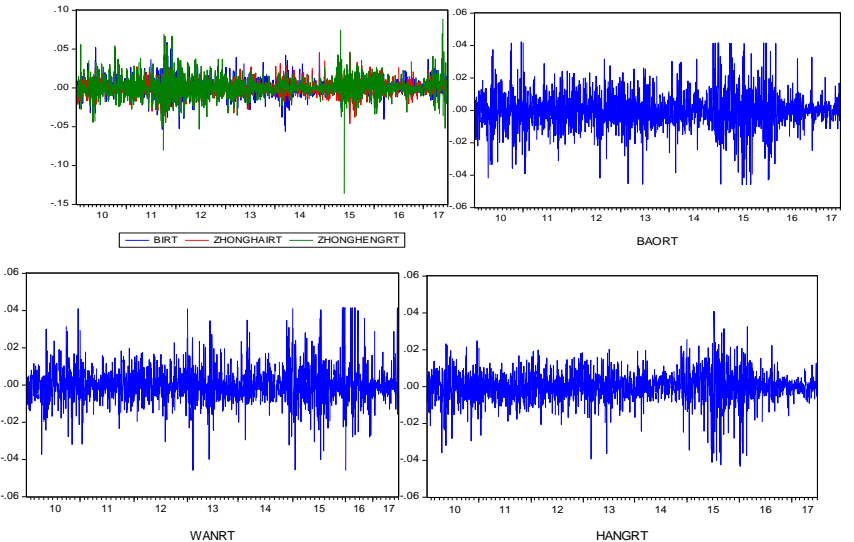

Fig. 1. Time series of daily returns of five listed companies and industry indices

Through the characterization of the sequence of samples, we can see the change of the sample sequence (see Figure 1). As can be seen from Figure 1, the daily returns of the five listed companies and the real estate industry index show a certain degree of volatility and aggregation in the sample interval, and occasionally there are large fluctuations, the aggregation is more obvious. And it always randomly fluctuates near a constant value of 0 . The range of fluctuation is bounded, there is no obvious trend, and periodic characteristics.

\section{B. Descriptive statistical analysis}

Through preliminary statistical analysis, descriptive statistics of sample data can be obtained. As shown in TABLE1, from the perspective of skewness, the daily returns of the five listed companies and the real estate industry index are asymmetric around their mean, positive skew means rightbiased; come from kurtosis and JB statistics Look, the daily returns of the five companies and the industry index do not obey the normal distribution; based on the above analysis, it can be found that the sample data has typical characteristics of financial data, namely the phenomenon of "spikes and thick tails”

TABLE I DESCRIPTIVE STATISTICS OF SAMPLE DATA

\begin{tabular}{|l|r|r|r|r|r|r|}
\hline & Poly Real Estate & Country Garden & $\begin{array}{c}\text { China Overseas } \\
\text { Construction }\end{array}$ & China Evergrande & Vanke Industry Index \\
\hline Mean & 0.000122 & 0.000354 & $7.67 \mathrm{E}-05$ & 0.000405 & 0.000271 & 0.000103 \\
\hline Median & 0 & 0 & 0 & 0 & 0.00038 \\
\hline Maximum & 0.042289 & 0.058835 & 0.069574 & -0.089123 & 0.041656 & 0.040855 \\
\hline Minimum & -0.045934 & -0.055825 & -0.051248 & -0.136382 & -0.045805 & -0.043228 \\
\hline Std. Dev. & 0.011706 & 0.011264 & 0.00964 & 0.013844 & 0.010414 & 0.008777 \\
\hline Skewness & -0.003603 & 0.1987 & 0.340763 & -0.109178 & 0.435131 & -0.649938 \\
\hline Kurtosis & 5.53177 & 6.203001 & 7.106948 & 11.72393 & 6.461676 & 6.649614 \\
\hline Jarque-Bera & 481.8118 & 799.9497 & 1330.915 & 5848.042 & 883.3456 & 1136.959 \\
\hline Probability & 0 & 0 & 0 & & 0 & 0 \\
\hline
\end{tabular}

\section{EMPIRICAL ANALYSIS}

\section{A. Inspection of data features}

- Stationary test

Prior to model estimation, the model needs to be tested for stationarity to prevent "pseudo-regression". Through the ADF test of the sample sequence, the results of the ADF test are shown in TABLE 2. The t-values of the unit root statistics of all listed companies and real estate industry indices are less than the critical levels of 1\%-10\% of ADF given by EVIEWS. The value, so reject the original hypothesis that the sequence is stable. Then you can do the next step analysis and modeling.

TABLE II UNIT ROOT TEST

\begin{tabular}{|c|c|c|c|c|c|c|}
\hline & $\begin{array}{c}\text { Poly Real } \\
\text { Estate }\end{array}$ & Country Garden & $\begin{array}{c}\text { China Overseas } \\
\text { Construction }\end{array}$ & $\begin{array}{c}\text { China } \\
\text { Evergrande }\end{array}$ & Vanke & Industry Index \\
\hline $\begin{array}{c}\text { Augmented } \\
\text { Dickey-Fuller } \\
\text { test statistic }\end{array}$ & -40.36226 & -41.44182 & -40.25458 & -31.49724 & -40.32012 & -30.0976 \\
\hline $1 \%$ level & -3.433747 & -3.433775 & -3.433699 & -3.433701 & -3.433699 & -3.43408 \\
\hline $5 \%$ level & -2.862927 & -2.862939 & -2.862906 & -2.862907 & -2.862906 & -2.863074 \\
\hline $10 \%$ level & -2.567555 & -2.567562 & -2.567544 & -2.567544 & -2.567544 & -2.567634 \\
\hline Prob.* & 0 & 0 & 0 & 0 & 0 & 0 \\
\hline
\end{tabular}


- Sequence correlation test

Before the ARCH-LM test, the lag order in the autoregressive equation needs to be determined. It can be known that only the Poly Real Estate is relevant among the five listed companies by analyzing the auto-correlation function charts of the returns of the five listed companies and the real estate industry index. The other four companies do not have autocorrelation; the real estate industry index also has autocorrelation.

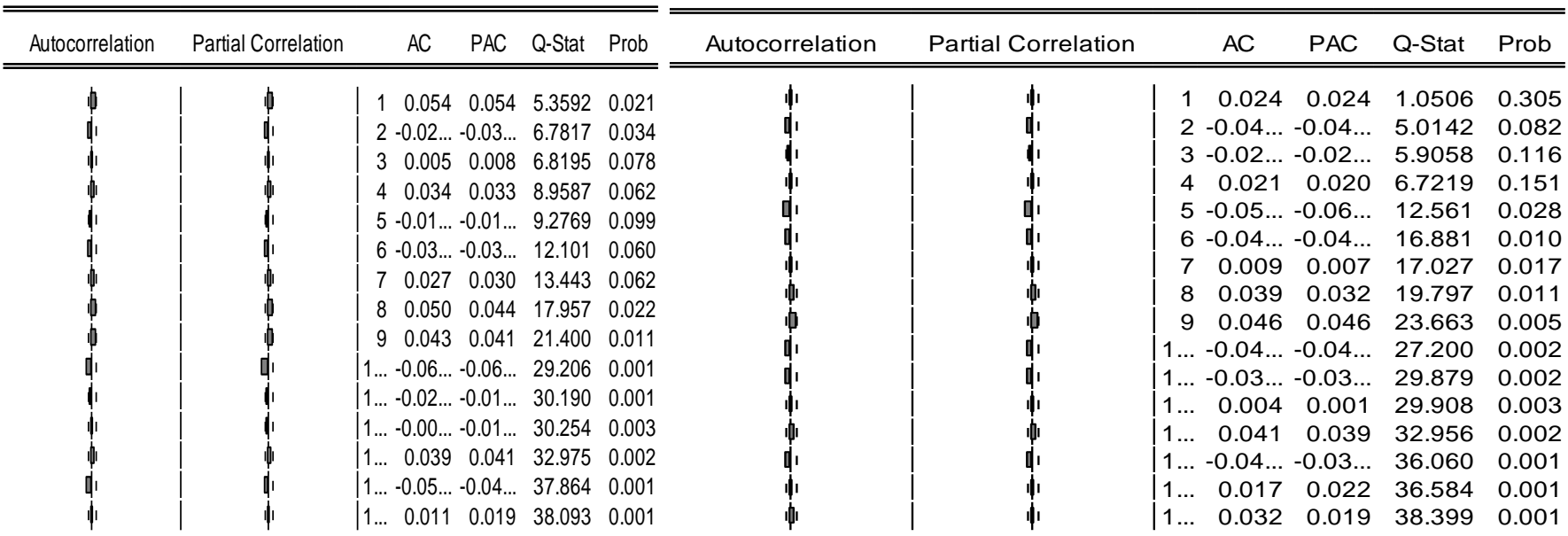

Fig. 2. Auto-correlation of Real Estate Industry Index and Poly Real Estate

From Figure 2, it can be seen that the real estate industry index and Poly Real Estate's auto-correlation coefficient always fluctuate around zero, and the sequence is determined to be a steady time series; looking at the $\mathrm{P}$ value of the $\mathrm{Q}$ statistic, the real estate industry index is smaller than the eighth order. 0.05, Poly Real Estate from the 5th order less than 0.05, the two are weakly related, so reject the original hypothesis, that the real estate industry index and Poly Real Estate's return rate series auto-correlation.

\section{B. The establishment of ARCH model}

\section{- ARMA modeling and ARCH test}

Based on the above analysis, the real estate industry index and Poly Real Estate's return rate series have auto-correlation, then ARMA modeling of these two sequences is performed. For the real estate industry index, by comparing ARMA models under different orders, the final model is $\operatorname{ARMA}(2,2)$; for Poly Real Estate, the final model is also $\operatorname{ARMA}(2,2)$. The analysis results are shown below:

\begin{tabular}{|c|c|c|c|c|}
\hline Variable & Coefficient & Std. Error & t-Statistic & Prob. \\
\hline $\begin{array}{l}\operatorname{AR}(1) \\
\operatorname{AR}(2) \\
M A(1) \\
M A(2)\end{array}$ & $\begin{array}{r}0.102184 \\
-0.945304 \\
-0.099022 \\
0.912812\end{array}$ & $\begin{array}{l}0.031603 \\
0.031410 \\
0.039600 \\
0.039373\end{array}$ & $\begin{array}{r}3.233339 \\
-30.09525 \\
-2.500525 \\
23.18345\end{array}$ & $\begin{array}{l}0.0012 \\
0.0000 \\
0.0125 \\
0.0000\end{array}$ \\
\hline $\begin{array}{l}\text { R-squared } \\
\text { Adjusted R-squared } \\
\text { S.E. of regression } \\
\text { Sum squared resid } \\
\text { Log likelihood } \\
\text { Durbin-Watson stat }\end{array}$ & $\begin{array}{l}0.010570 \\
0.008931 \\
0.008740 \\
0.138422 \\
6032.715 \\
1.893512\end{array}$ & \multicolumn{2}{|c|}{$\begin{array}{l}\text { Mean dependent var } \\
\text { S.D. dependent var } \\
\text { Akaike info criterion } \\
\text { Schwarz criterion } \\
\text { Hannan-Quinn criter. }\end{array}$} & $\begin{array}{r}0.000108 \\
0.008780 \\
-6.639555 \\
-6.627430 \\
-6.635081\end{array}$ \\
\hline
\end{tabular}

Fig. 3. ARMA $(2,2)$ Model of Real Estate Industry Index

\begin{tabular}{crrrr}
\hline \hline Variable & Coefficient & Std. Error & t-Statistic & Prob. \\
\hline AR(1) & 0.142131 & 0.019525 & 7.279502 & 0.0000 \\
MR(2) & -0.965950 & 0.019196 & -50.32023 & 0.0000 \\
MA(2) & -0.155755 & 0.024847 & -6.268545 & 0.0000 \\
R-squared & 0.944134 & 0.024461 & 38.59711 & 0.0000 \\
\hline \hline Adjusted R-squared & 0.010916 & Mean dependent var & 0.000130 \\
S.E. Of regression & 0.009266 & S.D. dependent var & 0.011708 \\
Sum squared resid & 0.011653 & Akaike info criterion & -6.064205 \\
Log likelihood & 0.244175 & Schwarzcriterion & -6.052004 \\
Durbin-Watson stat & 5467.849 & Hannan-Quinn criter. & -6.059701
\end{tabular}

Fig. 4. The ARMA (2,2) model of Poly Real Estate 
As can be seen from the above figures, both the real estate industry index and Poly Real Estate, the t-statistics of the parameter estimates of the model are significant, and the corresponding probability value $\mathrm{P}$ is very small, indicating that the model is very significant as a whole. Then the ARCH effect test is performed on the two sequences to determine whether the random error term exhibits "fluctuation aggregation" characteristics. The result is shown in the figures below:

Breusch-Godfrey Serial Correlation LM Test:

\begin{tabular}{llll}
\hline \hline F-statistic & 3.635177 & Prob. F(2,1810) & 0.0266 \\
Obs ${ }^{*}$ R-squared & 6.977925 & Prob. Chi-Square(2) & 0.0305 \\
\hline \hline
\end{tabular}

Fig. 5. ARCH-LM test of the residual sequence of the real estate industry index

Breusch-Godfrey Serial Correlation LM Test:

\begin{tabular}{llll}
\hline \hline & & & \\
F-statistic & 1.715279 & Prob. F(2,1796) & 0.1802 \\
Obs*R-squared & 3.199773 & Prob. Chi-Square(2) & 0.2019 \\
\hline \hline
\end{tabular}

Fig. 6. ARCH-LM test of Poly Real Estate Residual Series

From the above figures, we can see that the probability of the LM statistic of the real estate industry index is less than 0.05 , the LM value is known to fall to the right of the critical value, the original hypothesis is rejected, the ARCH effect exists in the residual sequence, and the sequence has the heteroscedasticity of the auto-regressive condition. The next step of GARCH modeling can be performed; however, the probability of LM statistics of Poly Real Estate is greater than 0.05, so accepting the original hypothesis, the residual has no $\mathrm{ARCH}$ effect.

\section{The establishment of GARCH model}

For the determination of the order of the GARCH model, this paper compares the $\operatorname{GARCH}(1,1), \operatorname{GARCH}(1,2)$, GARCH $(2,1)$ and $\operatorname{GARCH}(2,2)$ models under four different orders and finds GARCH. $(2,2)$ The estimated Z-statistic of the model parameters is not significant, so it is excluded that the parameter estimates of the other three models are in line with the requirements. Further based on the comparison of Log Likelihood, AIC, SC, to determine the optimal model. The comparison results are shown in the figure below:

TABLE III COMParison of GARCH Models with Different Lag Periods

\begin{tabular}{|c|c|c|c|}
\hline & GARCH $(1,1)$ & GARCH $(1,2)$ & GARCH(2,1) \\
\hline Log Likelihood & 6260.424 & 6264.087 & 6262.505 \\
\hline AIC & -6.882755 & -6.885685 & -6.883944 \\
\hline SC & -6.870642 & -6.870543 & -6.868802 \\
\hline
\end{tabular}

From the comparison of the above figure, the SC value of $\operatorname{GARCH}(1,2)$ is not the largest, but its $\log$ likelihood value (Log Likelihood) reaches the maximum, AIC reaches the minimum, and it also reaches statistical significance. Therefore, it is considered that the $\operatorname{GARCH}(1,2)$ model is better.

The GARCH $(1,2)$ model's estimation of the real estate industry index is:
Mean equation:

$r_{t}=0.102184 r_{t-1}-0.945304 r_{t-2}-0.099022 u_{t-1}+0.912812 u_{t-2}+u_{t}$ Variance equation:

$\sigma_{t}^{2}=1.36 E 07+0.018120 \sigma_{t}^{2}+1.736756 u_{t-1}^{2}-0.755924 u_{t-2}^{2}$

Residual auto-correlation and partial auto-correlation plots of the model: 


\begin{tabular}{|c|c|c|c|c|c|c|}
\hline Autocorrelation & Partial Correlation & & AC & PAC & Q-Stat & Prob... \\
\hline 中 & 中 & 1 & 0.041 & 0.041 & 3.0103 & 0.083 \\
\hline 1 & W & 2 & $-0.00 \ldots$ & $-0.00 \ldots$ & 3.0182 & 0.221 \\
\hline 1 & $\|$ & 3 & 0.008 & 0.008 & 3.1415 & 0.370 \\
\hline & $\|$ & 4 & 0.019 & 0.018 & 3.8007 & 0.434 \\
\hline & & 5 & $-0.00 \ldots$ & $-0.01 \ldots$ & 3.9426 & 0.558 \\
\hline & & 6 & $-0.01 \ldots$ & $-0.01 \ldots$ & 4.4565 & 0.615 \\
\hline W & $\|$ & 7 & 0.021 & 0.022 & 5.2803 & 0.626 \\
\hline$\|$ & $\|$ & 8 & 0.016 & 0.014 & 5.7517 & 0.675 \\
\hline (i) & p & 9 & 0.044 & 0.043 & 9.2592 & 0.414 \\
\hline 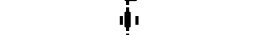 & 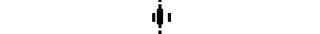 & $1 \ldots$ & $-0.00 \ldots$ & $-0.00 \ldots$ & 9.2671 & 0.507 \\
\hline d. & 1 & $1 \ldots$ & $-0.00 \ldots$ & $-0.01 \ldots$ & 9.4120 & 0.584 \\
\hline | & 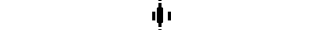 & $1 \ldots$ & 0.006 & 0.006 & 9.4843 & 0.661 \\
\hline & & & $-0.00 \ldots$ & $-0.01 \ldots$ & 9.6257 & 0.724 \\
\hline , & | & $1 \ldots$ & $-0.00 \ldots$ & $-0.00 \ldots$ & 9.6352 & 0.788 \\
\hline N & W & $1 \ldots$ & 0.017 & 0.019 & 10.194 & 0.807 \\
\hline 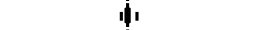 & 1 & $1 \ldots$ & 0.003 & $-0.00 \ldots$ & 10.214 & 0.855 \\
\hline$p$ & $\mid$ & $1 \ldots$ & 0.006 & 0.005 & 10.276 & 0.892 \\
\hline & i & & 0.032 & 0.030 & 12.185 & 0.838 \\
\hline
\end{tabular}

Fig. 7. Corrected residual squared correlation diagram

As shown above, it can be seen that the auto-correlation and partial auto-correlation are almost zero, and the $\mathrm{Q}$ statistic is not significant. Therefore, there is no heteroskedasticity in the residual squared sequence, indicating that the model estimation is better. Secondly, the sum of the ARCH and GARCH term coefficients is less than 1, which satisfies the constraints of the parameters, but because the sum of the coefficients is very close to one, it means that the impact on the conditional variance is persistent, that is, the impact plays an important role in the prediction of the future.

\section{The establishment of TARCH model}

The above GARCH model estimation assumes that there is a symmetry effect on the stock market shocks, but in real life, the stock market's impact often shows asymmetric effects. Negative shocks on stock indexes are more likely to fluctuate than on positive shocks, that is, there is a "leverage effect" in the stock market. In order to verify whether there is an asymmetric effect on the sample sequence, this paper uses the TARCH $(1,0)$ model to estimate the result as follows:

\begin{tabular}{|c|c|c|c|c|}
\hline Variable & Coefficient & Std. Error & z-Statistic & Prob. \\
\hline \multicolumn{5}{|c|}{ Variance Equation } \\
\hline $\mathrm{C}$ & $1.26 \mathrm{E}-06$ & $1.85 \mathrm{E}-07$ & 6.777533 & 0.0000 \\
\hline $\operatorname{RESID}(-1)^{\wedge} 2^{*}(\operatorname{RESID}(-1)<\ldots$ & 0.074244 & 0.008246 & 9.003479 & 0.0000 \\
\hline $\mathrm{GARCH}(-1)$ & 0.943280 & 0.005295 & 178.1385 & 0.0000 \\
\hline R-squared & -0.000138 & \multicolumn{2}{|c|}{ Mean dependent var } & 0.000103 \\
\hline Adjusted R-squared & 0.000412 & \multicolumn{2}{|c|}{ S.D. dependent var } & 0.008777 \\
\hline S.E. of regression & 0.008775 & \multicolumn{2}{|c|}{ Akaike info criterion } & -6.839236 \\
\hline Sum squared resid & 0.140001 & \multicolumn{2}{|c|}{ Schwarz criterion } & -6.830151 \\
\hline Log likelihood & 6219.866 & \multicolumn{2}{|c|}{ Hannan-Quinn criter. } & -6.835884 \\
\hline
\end{tabular}

Fig. 8. TARCH(1,0) model estimation results

As shown in the above figure, the estimated coefficient of the asymmetric effect (ie, leverage effect) is 0.074244 , which is significantly greater than zero, indicating that the fluctuation of the real estate industry index has a "leverage effect" , and the stock price decline is higher than the same level of increase.
More volatile. Since the model does not contain ARCH terms, the impact of good news on volatility is zero, and the impact of bad news on volatility is $0.074244 u_{t-1}^{2}$. Next, test the residual $\mathrm{ARCH}$ effect of the established TARCH model to determine if the model is valid. The results are as follows:

\begin{tabular}{ccccc}
\hline \hline Variable & Coefficient & Std. Error & t-Statistic & Prob. \\
\hline \hline C & 0.976892 & 0.053644 & 18.21063 & 0.0000 \\
WGT_RESID^2(-1) & 0.023508 & 0.023467 & 1.001774 & 0.3166 \\
\hline \hline
\end{tabular}

Fig. 9. TARCH model test results 
As shown in the above figure, the $\mathrm{P}$ value of the model coefficient is much larger than 0.05 , so the coefficient is not significant, indicating that the model has no ARCH effect and the model estimation result is valid.

\section{CONCLUSION}

This article uses the GARCH and TARCH models and empirically studies the volatility characteristics of China's real estate stock market by taking China's real estate industry index and China's representative five real estate listed companies as examples. Get the following conclusions:

(1) Through analyzing the auto-correlation function charts of the returns of the five listed companies and the real estate industry index, we can see that only Poly Real Estate is relevant among the five listed companies, and there is no autocorrelation among the other four companies; real estate industry index. There is also auto-correlation.

(2) The daily return fluctuations of Poly Real Estate and the real estate industry index are aggregated and persistent, and all exhibit a certain degree of auto-correlation. However, Poly Real Estate does not have heterogeneity, and the real estate industry index has a certain heterogeneity.

(3) As the real estate industry index has heteroskedasticity, GARCH and TARCH modeling of the real estate industry index is further known: The real estate industry index has asymmetric shocks, and bad news can produce greater results than the same amount of good news. Volatility, the volatility of the industry index's yield has a significant leverage effect.
The real estate industry, as a major part of the Chinese industry, is closely related to people's lives. Understanding the volatility characteristics of China's real estate stock market not only provides a theoretical basis for government departments to formulate macroeconomic policies, but also provides guidance for investors' investment decisions.

\section{REFERENCES}

[1] Wu Chongfeng, Wang Haicheng, Wu Wenfeng. Financial Engineering Research [M]. Shanghai Jiaotong University Press, 2000: 387-389.(In Chinese)

[2] I.-Yuan Chuang, Jin-Ray Lu, Pei-Hsuan Lee. Forecasting volatility in the financial markets: a comparison of alternative distributional assumptions. 2007 (13).

[3] Hung-Chun Liu; Jui-Cheng Hung. Forecasting SAP-100 Stock Index Volatility. The Role of Volatility Asynmetry and Distributional Assumption in GARCH Models. 2010(07).

[4] Md.Sabiruzzaman Model and Forecasting Trading Volume Index GARCH versus TGARCH Approach 2010(02).

[5] Wu Zhen, Zheng Wei. Prediction of stock price volatility based on wave theory and clustering wavelet packets [J]. Journal of Harbin Institute of Technology, 2004, 36(9): 72-75. (In Chinese)

[6] Wang Mingzhao, Guo Bing. Empirical study on the characteristics of volatility in Shanghai and Shenzhen stock markets [J]. Statistical Observations, 2004, 32(12). (In Chinese)

[7] JIA Fanglin. Analysis of the Causes of Stock Price Fluctuation in China [J]. Statistical Observation, 2003, 26 (13): 46-48. (In Chinese)

[8] Wu Xing, Zhang Hong, Zhang Xin. A study on the evaluation of the comprehensive strength of real estate listed companies in China [J]. China Real Estate Finance, 2003, 29(9):23-26. (In Chinese)

[9] Chen Zhaodong, Ren Hong, Huang Yongwei. Methods of analyzing the stock value of listed real estate companies [J]. Journal of Chongqing Jianzhu University, 2001, 32(2): 61-64. (In Chinese) 